\title{
REVIEW ARTICLE \\ Experimental modeling of hypoxia in pregnancy and early postnatal life
}

\author{
Mojmír MACH ${ }^{1}$, Michal DUBOVICKÝ 1, Jana NAVAROVÁ 1, Ingrid BRUCKNEROVÁ 2 , Eduard UJHÁZY 1 \\ 1 Institute of Experimental Pharmacology \& Toxicology, Slovak Academy of Sciences, Bratislava, Slovakia \\ 2 st Department of Pediatrics, Medical School, Comenius University, Bratislava, Slovakia
}

ITX020109A05 • Received:2 February 2009 • Revised: 25 February 2009 • Accepted: 15 March 2009

\begin{abstract}
The important role of equilibrium of environmental factors during the embryo-fetal period is undisputable. Women of reproductive age are increasingly exposed to various environmental risk factors such as hypoxia, prenatal viral infections, use of drugs, smoking, complications of birth or stressful life events. These early hazards represent an important risk for structural and/or functional maldevelopment of the fetus and neonates. Impairment of oxygen/energy supply during the pre- and perinatal period may affect neuronal functions and induce cell death. Thus when death of the newborn is not occurring following intrauterine hypoxia, various neurological deficits, including hyperactivity, learning disabilities, mental retardation, epilepsy, cerebral palsy, dystonia etc., may develop both in humans and in experimental animals. In our animal studies we used several approaches for modeling hypoxia in rats during pregnancy and shortly after delivery, i.e. chronic intrauterine hypoxia induced by the antiepileptic drug phenytoin, neonatal anoxia by decreased oxygen saturation in 2-day-old pups. Using these models we were able to test potential protective properties of natural (vitamin E, melatonin) and synthetic (stobadine) compounds. Based on our results, stobadine was also able to reduce hypoxia-induced hyperactivity and the antioxidant capacity of stobadine exceeded that of vitamin E and melatonin, and contrary to vitamin E, stobadine had no adverse effects on developing fetus and offspring.
\end{abstract}

KEY WORDS: hypoxia; pregnancy; animal models; behavior; antioxidants

\section{Introduction}

Hypoxia during pregnancy, labor or early life stage is a major determinant of neurological morbidity and mortality in the neonatal period. Many studies have been investigating neurological deficits following perinatal hypoxia, including seizures, cerebral palsy, mental retardation, attention deficit-hyperactivity disorder, anxiety as well as other mental diseases. (Volpe, 1995; Golan et al., 2004; Bhat et al., 2005). Insufficient delivery of the tissue energy reserves (oxygen, nutrients) to the developing brain threatens its function during entire life-span up to senescence (Nyakas et al., 1996), and it might be one of primary factors in the pathogenesis of neurodegenerative diseases.

In the last decade the fetal origin of chronic adult diseases was proposed as the most important factor in genesis of diabetes and hypertension in adulthood. The scientists showed that malnutrition, and inadequate oxygen supply

Correspondence address

Mojmír Mach, PhD.

Dept. Reproductive Toxicology,

Institute of Experimental Pharmacology \& Toxicology, Slovak Academy of Sciences Dúbravská cesta 9, 84104 Bratislava, Slovakia

E-MAll: mojmir.mach@savba.sk during embryofetal development may lead to the inadequate apoptosis/necrosis (do Carmo Pinho Franco et al., 2003, Barker, 1998) and caused maldevelopment of the organs responsible for regulation blood pressure (kidneys) and glucose (pancreas) (Barker, 1998; Bezek et al., 2008).

Although the understanding of perinatal asphyxiarelated pathophysiology is gradually increasing, limited therapeutic options are available to prevent or even mitigate the devastating process that unfolds after injury (Brucknerová et al., 2008). A potential solution lies in the application of therapeutic hypothermia, protective use of antioxidants (Ujházy et al., 2006, Hoeger et al., 2006)

A study of hypoxia causing brain damage in the guinea pig was the first confirmation of the importance of fetal asphyxia (Windle and Becker, 1942). Since that time a number of research models have examined the effect of asphyxia in the fetal monkey, fetal lamb and laboratory rodents. Asphyxia has been induced by maternal hypoxemia, reduced utero-placental blood flow, umbilical cord occlusion, neonatal anoxia in 2-day old pups, while cerebral ischemia has been caused by carotid artery occlusion. (Dell'Anna et al., 1991; Lubec at al., 1997; Pulera et al., 1998; Spandou et al., 1999)

Numerous exposures to drugs or physical treatment (uterine vascular clamping, calcium channel blockers, phenytoin, cocaine, nitric oxide synthase inhibitors, chorionic 
villus sampling) have been shown to induce limb and central nervous system (CNS) defects in developing rats when the exposure occurs during fetal stages. Although it is a chemically and physically diverse group, exposure to each of the chemicals or events studied has been found to have vasoactive or cardioactive consequences that result in transient uteroplacental hypoperfusion (Fantel and Person, 2002).

\section{Hypoxia in pregnancy}

Hypoxia can produce temporary brain dysfunction or permanent brain injury, depending on the duration, intensity of oxygen deprivation and age of the fetus. The hypoxia/ ischemia cascade leads to neuronal cell death through overstimulation of the excitatory amino acid receptors (Monaghan et al., 1989; Olney, 1989), cellular calcium influx, and formation of free radicals and nitric oxide.

The results of several studies implicate that the neurotoxicity resulting from overstimulation of the excitatory amino acid receptor is extremely active in the immature rat brain compared to the adult rat brain (McDonald et al., 1988). Prenatal hypoxia frequently occurs during maternal convulsions in preeclampsia or eclampsia conditions. Severe asphyxia can occur in infants around the time of birth for several reasons, including compression of the umbilical cord, abruption of the placenta, abnormal uterine contractions, or failure of the neonate to successfully begin breathing. Another risk for embryo-fetus/child neurodevelopment is disruption of the milieu and integrity between mother and fetus by stress, drugs and especially the conditions leading toward excessive free radical generation.

Acute perinatal asphyxia is a major cause of death and neurological injury in newborn infants. The incidence has been estimated as 1-6 per 1000 live births and has not decreased despite advances in perinatal and obstetric care. Many asphyxiated babies die during the newborn period, and $20-30 \%$ of the survivors present with long term neurological sequelae, including spasticity, epilepsy, and mental retardation. Neurodevelopmental abnormality in childhood, presenting as seizure activity and/or motor impairment similar to that which may be observed in children with cerebral palsy, may result in the severe cases (Tuor et al., 1996). Milder forms of asphyxiating insults can be associated with learning disabilities and attention deficit disorders, such as the minimal brain disorder syndrome (Volpe, 1987; Hill, 1991; Carter et al., 1993).

\section{Experimental approaches}

Gravity of hypoxia during pregnancy and in the early postnatal period brings us to the problem how we can improve the strategy of prevention and treatment of hypoxic-ischemic complications. Researchers developed several methodological approaches using animal models as a useful tool for elucidation of this problem. The most sensitive period for brain development is time around and shortly after delivery. From this point of view rats are suitable model. It well known that the relationship between birth and brain maturation varies substantially between species (Dobbing and Sands, 1979). The CNS of rats and mice, the most often used species for mechanistic studies in hypoxia/ischemia, is relatively immature at birth and therefore could mimic critical stages of third trimester in humans. Ligation of commom carotic artery (bilateral or unilateral) in 5-7 days old rat pups, with/ without systemic oxygen decrease, is very often model for studying hypoxia/ischemia complications (Pulera et al., 1998; Spandou et al., 1999). Bilateral carotid occlusion in the 5-day-old rat, without accompanying hypoxia, causes preferential white matter injury (Uehara et al., 1999) with only scattered neuronal injury within the cortex. This model holds a great deal of promise for the study of mild to moderate handicap that is associated with ventriculomegaly but minimal other detectable neuropathology.

Another approach is using much younger rat pups (1-2 days old) and provokes anoxia in nitrogen atmosphere of tight sealed glass chamber. Adapting the Dell'Anna et al. (1991) model to the extremely immature rat has also revealed some important developmental differences in injury susceptibility (Sheldon et al., 1996). These extremely immature (postnatal day 1-2) animals require a longer and more severe degree of hypoxia to produce injury compared with postnatal day 7 rats, and there is a greater degree of damage to the ipsilateral subcortical developing white matter than in older rats (Sheldon et al., 1996).

Above mentioned approaches represent acute models hypoxia/ischemia. However, hypoxia/ischemia is often caused also with chronic hypoxia-reoxygenation during maturation of organs. For this sake the model of chronic intrauterine hypoxia induced pharmacologically (phenytoin - PHT) was introduced by our lab. The proposed teratogenicity mechanism of antiseizure medication phenytoin is due to embryonic hypoxia/ischemia and production of free radicals (Danielsson et al., 1997; Wells and Winn, 1996; Figure 1).

\section{Neonatal anoxia in 2-day-old rat pups}

This model represents non-invasive approach of hypoxia/ ischemia study in young rat pups, what is the biggest advantage compared to carotid occlusions. It was introduced by Dell'Anna et al. (1991) and provides wide range of settings, i.e. temperature, age, $\mathrm{O}_{2}$ concentration, with minimal mother-pup unit interference. Anoxia is induced in a glass chamber with tempered bottom and cover connected to the nitrogen supply. Pups are placed into the chamber and the air inside is removed by a stream of nitrogen gas and the pups are exposed to normobaric anoxia. After anoxic insult all pups are replaced to their mothers and not surviving pups are removed.

\section{PHT induced chronic intrauterine hypoxia}

Several mechanisms underlying PHT teratogenicity have been proposed, including disturbances in folate metabolism (Monie et al., 1961), vitamin K metabolism (Howe et al., 1995), and bioactivation of PHT to a reactive toxic intermediate (epoxide) by cytochrome P450 (Cyp450) (Martz et al., 


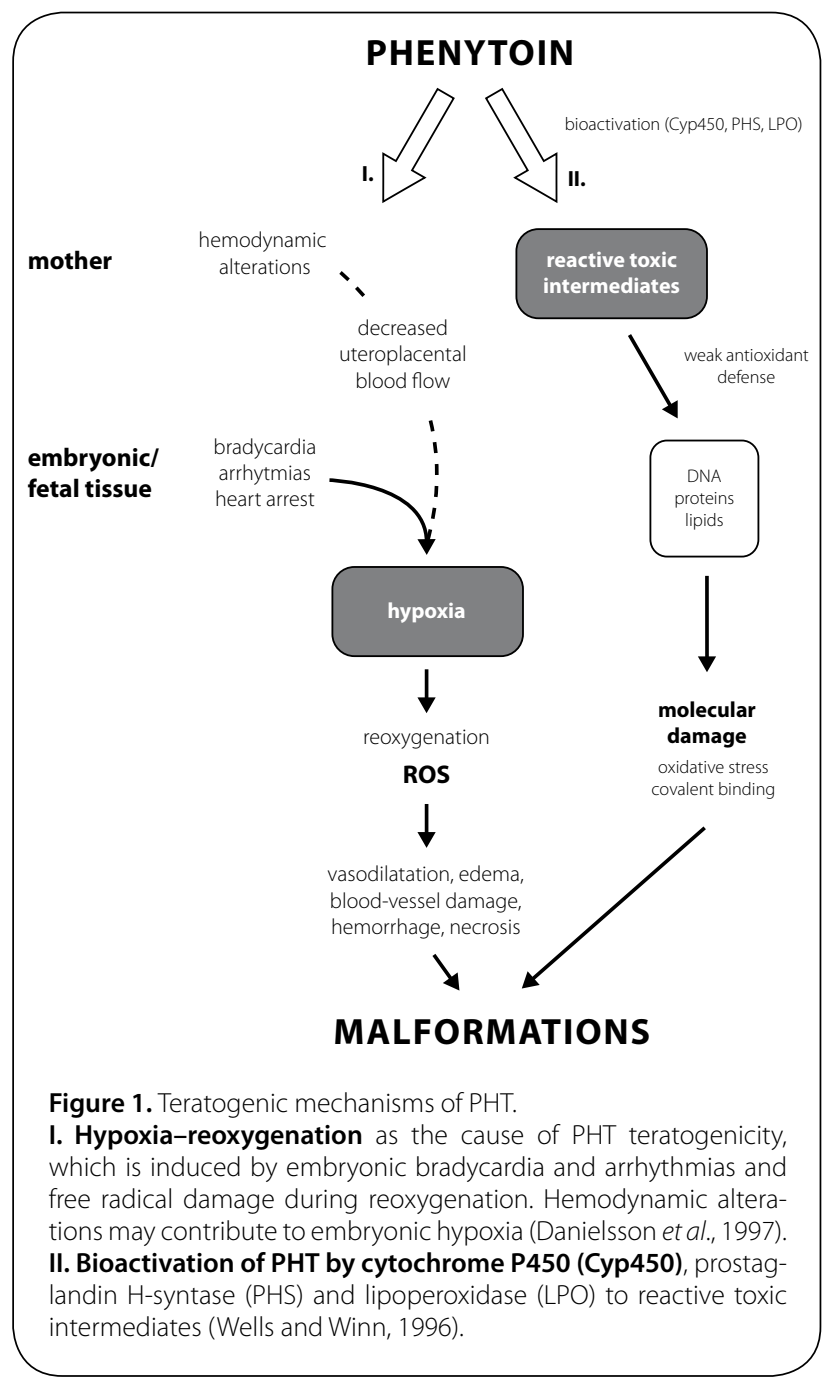

1977), or co-oxidation of PHT to free radical intermediates centered in the hydantoin nucleus (Wells and Vo, 1989).

One theory suggests that PHT teratogenicity is mainly initiated by adverse pharmacological action on the embryonic heart during a sensitive stage of development, resulting in embryonic hypoxia/ischemia (Azarbayjani and Danielsson, 1998). Maternal hemodynamic alterations may contribute to embryonic hypoxia, but these alterations are not of a magnitude by which they alone could explain the observed hypoxia-related malformations (Danielson et al., 1992). Embryonic hypoxia has been associated with specific pathological changes such as vascular disruption, hemorrhage, and finally tissue necrosis of embryonic tissues (Danielson et al., 1992). The tissue necrosis, manifested as malformations in the fetus at term, may be a direct consequence of hypoxia and/or generation of ROS at reoxygenation (Figure 1).

In our experiments PHT was given to pregnant rats dissolved in deionized distilled water and $\mathrm{pH}$ was adjusted to 11.5 with $\mathrm{NaOH}$. Buffer water with $\mathrm{pH} 11.5$ was used as a control vehicle. The dams could be treated by oral gavage with PHT $(150 \mathrm{mg} / \mathrm{kg})$ daily in sensitive stages of organ development or during whole pregnancy (Ujházy et al., 2000).

\section{Hypoxia induced structural and functional disturbances: possible pharmacological intervention with antioxidants}

Animal models represent one and only tool for assessing disturbances during development. The observations in humans (blood draw, biochemical analysis, behavioral scans) could by make only after insult and therefore the data represents changes not mechanisms. In this matter animals are used for elucidation of mechanisms leading to origins of eclampsia, placental transfer disturbances, maternal-fetal complex communications etc. For extrapolation to humans, threshold effect and intra-/interspecies differences in the timing of developmental events must also be taken into account (Hogan and Hoel, 1989).

As we mentioned above, hypoxia represents serious risk factor in human development. Two experimental models of hypoxia (acute and chronic) were used for assessment not only structural disturbances (teratology studies) but also functional disorders (behavioral studies). Neonatal anoxia showed that 1- and 2-day old rat pups were extremely resistant to anoxic insult (Dubovický et al, 2000). Despite the mild disturbances after anoxia we were able to detect hyperactivity in male offspring (Ujházy et al., 2006). Interestingly, the synthetic pyridoindole antioxidant stobadine (STO) was able to reduce this hyperactivity, suggesting crucial role of reactive oxygen species in mechanism of anoxia induced behavioral disturbances (Ujházy et al., 2006). The protective effect of hypothermia following an asphyxiating insult was first demonstrated by the pioneering work of Miller (1971). Following this, several studies have confirmed the effectiveness of both intra- as well as post-asphyxic hypothermia. Similar to these findings or experiment confirmed importance of temperature in neonatal hypoxia, especially acute form. Moreower, the age factor is playing the important factor as well (Figure 2).

We studied also the effect of chronic intrauterine hypoxia produced by PHT on pre- and postnatal development of the rat offspring. When administered prenatally, PHT (inductor of hypoxia in prenatal development) was shown to exert an overwhelming effect on embryo-fetal and neuromotor development (Ujházy et al., 2000; Mach et al., 2001). It was reported that prenatal PHT treatment of rats is increasing catecholamine release in response to a mild stressor in adulthood (Makatsori et al., 2005). The pretreatment of pregnant rats with STO $2 \mathrm{~h}$ prior PHT administration partially decreased the embryotoxic effect of PHT, as manifested by increase of fetal and placental weight compared to the PHT group, and exerted a positive influence on some reproductive variables (live fetuses, resorptions, pre- and postimplantation loss) (Ujházy et al., 2004). The supplementation with a high dose of the natural antioxidant vitamin E (VitE) did not ameliorate the developmental toxicity of PHT and failed to protect the rat fetuses. Moreover, VitE induced growth retardation, apparent also in adulthood. Our results indicate insufficient protection of antioxidants (VitE, melatonin) in the PHT model (Mach et al., 2005; 2006). Prenatally administered PHT in the dose of $150 \mathrm{mg} / \mathrm{kg}$ is probably too toxic for the mother and 


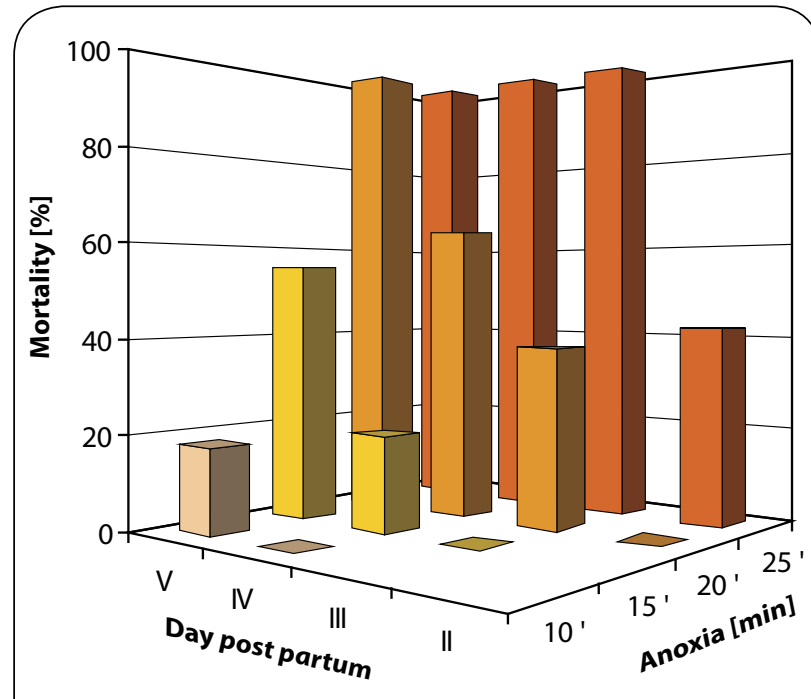

Figure 2. Increase of pups mortality dependent on age and duration of anoxic insult. ( $n=40-80$ pups/group).

developing fetus so that antioxidants are unable to eliminate oxidative stress. Surprisingly, we found that high doses of VitE in pregnancy, which should be safe, appear to involve a risk to the developing rat fetus due to the occurrence of slight skeletal anomalies and persistent growth retardation apparent up to adulthood (Mach et al., 2006).

\section{Conclusions}

The aim of our experiments is to widen our knowledge on the possible protective effects of antioxidants in a hypoxia/ ischemia models. Based on our results, the antioxidant capacity of STO exceeded that of VitE, and contrary to VitE, STO had no adverse effects on offspring. Even though STO did not fully alleviate the PHT teratogenicity, it was able to reduce $\mathrm{PHT}$-induced hyperactivity and had beneficial effects on some reproductive variables. These results are indicative of a prospective use of STO as a potential protectant and a supportive therapeutic agent in pregnancies with high risk of pre-eclampsia, perinatal asphyxia or pre-term delivery, in which oxidative injury may play a crucial role.

The experimental results also demonstrating that ethological approaches in pharmacology and toxicology are an integral part of relative safety drug assessment (Dubovický et al., 2008). Further experiments with animal models are needed, so more accurate and precise insights into the mechanisms of hypoxia induced brain injury and sequels could be successfully treated or et least managed on the bearable level.

\section{Acknowledgement}

This work was supported by the grants VEGA 2/0083/08 and $2 / 0066 / 09$.

\section{REFERENCES}

Azarbayjani F and Danielsson BR. (1998). Pharmacologically induced embryonic dysrhythmia and episodes of hypoxia followed by reoxygenation: a common teratogenic mechanism for antiepileptic drugs? Teratology 3: 117-126.

Barker SD. (1998). In utero programming of chronic disease. Clin Sci (Lond) 95 115-128.

Bezek Š, Ujházy E, Mach M, Navarová J, Dubovický M. (2008). Developmental origin of chronic diseases: chronic implication. Interdisc Toxicol 1(1): 29-31.

Bhat M, Grizenko N, Ben-Amor L, Joober R. (2005). Obstetric complications in children with attention deficit/hyperactivity disorder and learning disability. McGill Journal of Medicine 8(2): 109-113.

Brucknerová I, Ujházy E, Dubovický M, Mach M. (2008). Early assessment of the severity of asphyxia in term newborns using parameters of blood count. Interdisc Toxicol 13(3-4): 211-213.

Carter BS, Havercamp AD, Merenstein GB. (1993). The definition of acute perinatal asphyxia. Clin Perinato/ 20: 287-303.

Danielson MK, Danielsson BR, Marchner H, Lundin M, Rundqvist E, Reiland S. (1992). Histopathological and hemodynamic studies supporting hypoxia and vascular disruption as explanation to phenytoin teratogenicity. Teratology5: 485-497.

Danielsson BR, Azarbayjani F, Skold AC, Webster WS. (1997). Initiation of phenytoin teratogenesis: pharmacologically induced embryonic bradycardia and arrhythmia resulting in hypoxia and possible free radical damage at reoxygenation. Teratology 4: 271-281.

Dell'Anna E, Calzolari S, Molinari M, luvone L, Calimici R. (1991). Neonatal anoxia induced transitori hyperactivity, permanent spatial memory deficits and CA1 cell density reduction in developing rats. Behav Brain Res 45: 125-134.

do Carmo Pinho Franco M, Nigro D, Fortes ZB, Tostes RC, Carvalho MH, Lucas SR, Gomes GN, Coimbra TM, Gil FZ. (2003). Intrauterine undernutrition-renal and vascular origin of hypertension. Cardiovasc Res. 60(2): 228-234.

Dobbing J, Sands J. (1979). Comparative aspects of the brain growth spurt. Early Hum Dev 3: 79-83.

Dubovický M, Mach M, Ujházy E, Juránek I, Navarová J, Kovačovský P, Rychlík I, Sadloňová I. (2000). Effect of neonatal anoxia on neurobehavioral development of rats. Biologia 55(Suppl. 8): 27-32.

Dubovický M, Kovačovský P, Ujházy E, Navarová J Brucknerová I, Mach M. (2008). Evaluation of developmental neurotoxicity: some important issues focused on neurobehavioral development. Interdisc Toxicol 1 (3-4): 206-210.

Fantel AG, Person RE. (2002). Involvement of mitochondria and other free radical sources in normal and abnormal fetal development. Ann NY Acad Sci 959 424-433.

Golan H, Kashtutsky I, Hallak M, Sorokin Y, Huleihel M. (2004). Maternal hypoxia during pregnancy delays the development of motor reflexes in newborn mice. Dev Neurosci 26(1): 24-29.

Hill A. (1991). Current concepts of hypoxic-ischemic cerebral injury in the term newborn. Pediatr Neurol 7: 317-325.

Hoeger H, Engidawork E, Stolzlechner D, Bubna-Littitz H, Lubec B. (2006). Longterm effect of moderate and profound hypothermia on morphology, neurological, cognitive and behavioural functions in a rat model of perinatal asphyxia. Amino Acids 31(4): 385-396.

Hogan MD, Hoel DG. (1989). Extrapolation to man. In. Principles and Methods in Toxicology Hayes, A.W., ed., Raven Press, New York, pp. 879-891.

Howe AM, Lipson AH, Sheffield LJ, Haan EA, Halliday JL, Jenson F, David DJ, Webster WS. (1995). Prenatal exposure to phenytoin, facial development, and a possible role for vitamin K. Am J Med Genet 58: 238-244.

Lubec B, Dell'Anna E, Fang-Kircher S, Marx M, Herrera-Marschnitz M, Lubec G. (1997). Decrease of brain protein kinase c, protein kinase a, cyclin-dependent kinase correlating with ph precedes neuronal death in neonatal asphyxia. Invest Med 45: 284-294. 
32 Experimental modeling of hypoxia in pregnancy and early postnatal life

M. Mach, M. Dubovický, J. Navarová, I. Brucknerová, E. Ujházy

Mach M, Dubovický M, Navarova J, Kovačovský P, Ujházy E. (2006). Vitamin E supplementation in phenytoin induced developmental toxicity in rats: postnatal study. Neuro Endocrinol Lett 27 Suppl 2: 69-73.

Mach M, Ujházy E, Dubovický M, Kovačovský P, Navarová J. (2005). High-dose vitamin E supplementation in phenytoin induced intrauterine hypoxia: teratological study. Biologia 60 Suppl. 17: 45-49.

Mach M, Ujházy E, Dubovický M, Navarová J, Blažíček P, Šoltés L. (2001). Structural and functional changes in rat offspring induced by prenatal phenytoin administration. Med Mil Lett LXX Suppl 2: 79-82.

Makatsori A, Dubovický M, Ujházy E, Bakoš J, Ježová D. (2005). Neuroendocrine changes in adult female rats prenatally exposed to phenytoin. Neurotoxicol Terato/ 27: 509-514.

Martz F, Failinger C III., Blake DA. (1977). Phenytoin teratogenesis: Correlation between embryopathic effect and covalent binding of putative arene oxide metabolite in gestational tissue. J Pharmacol Exp Ther 203: 231-239.

McDonald JW, Silverstein FS, Johnston MV. (1988). Neurotoxicity of N-methyl- D -aspartate is markedly enhanced in developing rat central nervous system. Brain Res 459: 200-203.

Miller JA. (1971). New approaches to preventing brain damage during asphyxia. Am J Obstet Gynecol 110(8): 1125-1133.

Monaghan DT, Bridges RJ, Cotman CW. (1989). The excitatory amino acid receptors: Their classes, pharmacology, and distinct properties in the function of the central nervous system. Annu Rev Pharmacol Toxicol 29: 365-402.

Monie IW, Armstrong RM, Nelson MM. (1961). Hydrocephalus and other abnormalities in rat young resulting from maternal pteroylglutamic acid deficiency from the 8th to 10th days of pregnancy. Teratology 1: 8 .

Nyakas C, Buwalda B, Luiten PGM. (1996). Hypoxia and brain development. Prog Neurobio/ 49: 1-51.

Olney JW. (1989). Excitotoxicity and N-methyl-D-aspartate receptors. Drug Dev Res 17: 299-319.

Pulera MR, Adams LM, Liu H, Santos DG, Nishimura RN, Yang F, Cole GM, Wasterlain CG. (1998). Apoptosis in a neonatal rat model of cerebral hypoxia-ischemia. Stroke 29: 2622-2630.
Sheldon RA, Chuai J, Ferriero DM. (1996). A rat model for hypoxic-ischemic brain damage in very premature infants. Biol Neonate 69: 327-341.

Spandou E, Karkavelas G, Soubasi V, Avgovstides-Savvopoulou P, Loizidis T, Guiba-Tziampiri O. (1999). Effect of ketamine on hypoxic-ischemic brain damage in newborn rats. Brain Res 819: 1-7.

Tuor UI, Del Bigio MR, Chumas PD. (1996). Brain damage due to cerebral hypoxia/ischemia in the neonate: pathology and pharmacological modification. Cerebrovascular \& Brain Metabolism Review 8: 159-193.

Uehara H, Yoshioka H, Kawase S, Nagai H, Ohmae T, Hasegawa K, Sawada T. (1999). A new model of white matter injury in neonatal rats with bilateral carotid artery occlusion. Brain Res 837: 213-220.

Ujházy E, Dubovický M, Mach M, Juránek I, Navarová J, Sadloňová I, Gajdošík A. (2000). Effect of phenytoin on prenatal and postnatal development of rats. Biologia 55: 125-130.

Ujházy E, Mach M, Dubovický M, Navarova J, Šoltés L, Juránek I, Brucknerová I, Zeman M. (2004). Effect of melatonin and stobadine on maternal and embryofoetal toxicity in rats due to intrauterine hypoxia induced by phenytoin administration. Cent Eur J Public Health 12 Suppl: S83-S86.

Ujházy E, Schmidtová M, Dubovický M, Navarová J, Brucknerová I, Mach M. (2006). Neurobehavioural changes in rats after neonatal anoxia: effect of antioxidant stobadine pretreatment. Neuro Endocrinol Lett 27 Suppl 2: 82-85.

Volpe JJ. (1995). Hypoxic-ischemic encephalopathy; in Neurology of the Newborn, Volpe, J. J., ed., Philadelphia, Saunders, pp. 211-369.

Volpe JJ. (1987). Neurology of the newborn. In: Hypoxic-ischemic encephalopathy: biochemical and physiological aspects. Volpe JJ, ed., WB Saunders, Philadelphia, p.22.

Wells PG. Vo HPN. (1989). Effects of the tumor promoter 12-0-tetradecanolylphorbol-13-acetate on phenytoin-induced embryopathy in mice. Toxicol Appl Pharmacol 97: 398-405.

Wells PG, Winn LM. (1996). Biochemical toxicology of chemical teratogenesis. Crit Rev Biochem Mol Biol 1: 1-40

Windle WF, Becker RF. (1942). Effect of anoxia at birth on the central nervous system of the guinea pig. Proc Soc Exp Biol Med 51: 213-219. 